\title{
The Effects of Exercise and Massage on Disuse Muscle Atrophy in Special Focus on Mechanical Stress
}

\author{
Kumiko Saitou ${ }^{1}$ and Katsuhiko Suzuki ${ }^{2 *}$ \\ ${ }^{1}$ Graduate School of Sport Sciences, Waseda University, Mikajima, Tokorozawa, Saitama, Japan \\ ${ }^{2}$ Faculty of Sport Sciences, Waseda University, Mikajima, Tokorozawa, Saitama, Japan
}

"Corresponding author: Katsuhiko Suzuki, Faculty of Sport Sciences, Waseda University, Mikajima, Tokorozawa, Saitama, Japan. Email: katsu.suzu@waseda.jp

Citation: Saitou K and Suzuki K (2019) The Effects of Exercise and Massage on Disuse Muscle Atrophy in Special Focus on Mechanical Stress. Int J Musculoskelet Disord 3: 115. DOI: 10.29011/IJMD-115.1000015

Received Date: 28 January, 2019; Accepted Date: 13 March, 2019; Published Date: 21 March, 2019

\begin{abstract}
Physical inactivity arises from a variety of health problems, including ageing, injury, and neuromuscular diseases, and can lead to numerous organismal disorders such as muscle atrophy. In addition to skeletal muscle atrophy, physical inactivity induces enhanced expression of pro-inflammatory factors, promoting inflammation in muscle tissues. Muscle atrophy and inflammation progress synergistically, aggravating physical inactivity. As a result, a vicious circle is formed by physical inactivity and muscle frailty. Physical exercise is recommended for prevention of muscle atrophy and inflammation. However, the molecular mechanisms underlying the benefits of exercise toward muscle atrophy are poorly understood. Whereas massage is a widespread alternative intervention and is considered to provide the physiological, biomechanical, neurological and psychological benefits, there remain controversies in the effectiveness of massage. In this review, we describe the associations among physical exercise, disuse muscle atrophy and massage with respect to mechanical stress on muscle tissues.
\end{abstract}

\section{Introduction}

Physical inactivity, the forth leading risk factor for death worldwide, kills more than 5 million people every year [1]. It arises from a variety of health problems, including ageing, injury, and neuromuscular diseases, and can lead to numerous organismal disorders such as muscle atrophy [2]. Inflammation, which involves enhanced expression or production of pro-inflammatory cytokines and chemokines, has been implicated in the pathology of disuse skeletal muscle atrophy [3,4]. Besides the chronic nature of inactivity-related inflammation [5], a vicious circle formed by physical inactivity and muscle frailty exacerbates decrease in muscle mass, resulting in irreversible deterioration of general bodily functions. Physical exercise has anti-inflammatory effects $[6,7]$, but the molecular mechanisms underlying the beneficial effects of exercise to organismal homeostasis are poorly delineated, especially with regard to its suppression of local inflammation. This problem may partially account for the small population participating in habitual exercise [8,9]. Massage is generally appreciated as a pain- or inflammation-relieving procedure and is beneficial for pain relief and improvement of physical performance for competitive athletes and non-athletes [10,11]. Massage suppresses local inflammation [12] and prompts recovery from exercise-induced muscle damage [13,14]. Although we know very little about the biochemical mechanisms behind the benefits of massage, there is a common feature between physical exercise and massage. They both generate local mechanical stress on organs, tissues and cells through deformation. This review article aims to outline the literature on disuse muscle atrophy, massage and the role of macrophages, especially with regard to mechanical stress. Understanding the mutual relationship during mechanical stress will lead to identification of novel mechanisms common to both physical activity and massage, and to develop exercise and massage as medical therapies based on scientific evidence.

\section{Materials and methods}

We performed an online search of the journal databases PubMed and Google Scholar. The following keywords were used as search terms in various combinations: disuse muscle atrophy, acute/chronic inflammation, monocyte/macrophage, monocyte chemoattractant protein (MCP)-1, cytokine, massage, mechanical stress and interstitial fluid flow. Articles, and articles cited in the reference lists of identified journals were selected based on their relevance and specificity. 


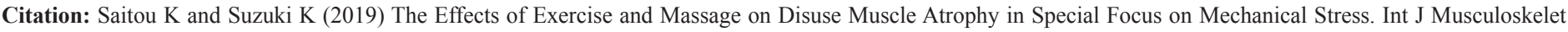
Disord 3: 115. DOI: 10.29011/IJMD-115.1000015

\section{Mechanisms of Disuse Skeletal Muscle Atrophy}

\section{Introduction of disuse atrophy}

Disuse muscle atrophy occurs due to chronic periods of inactivity, such as poor prognosis, bed rest and exposure to hypogravity [15-17]. Symptoms of muscle atrophy are mainly decrease in muscle volume, mass and myofibril cross-sectional area (CSA) and muscle weakness. Ogawa, et al. examined myofibril CSA in quadriceps femora's muscle from research subjects after 20 days of bed rest [15]. During bed rest, myofibril CSA decreased significantly by $3.7 \%$. Haus et al. reported that simulated microgravity, utilizing either unilateral lower limb suspension, or bed rest caused marked decreases in quadriceps femora's muscle volume (35 days of limb suspension: $-9 \%$ and 90 days of bed rest: $-18 \%$ ) and triceps surae muscle volume (35 days of limb suspension: $-11 \%$ and 90 days of bed rest: -29\%) [16]. Likewise, LeBlanc, et al. demonstrated that an evident decrease in muscle volume occurred in astronauts as a result of spaceflight ( 8 days of weightlessness): the triceps surae $(-6.3 \%)$, anterior calf $(-3.9 \%)$, hamstrings $(-8.3 \%)$, quadriceps $(-6.0 \%)$ and intrinsic back $(-10.3 \%)$ muscles [17]. On the other hand, several experiments have been conducted on disuse muscle atrophy using rodent models $[18,19]$. The extent of disuse muscle atrophy shown by the decreases in gastrocnemius muscle mass amounted to $15 \%$ or $25 \%$ after 7 days of hindlimb suspension or denervation, respectively [20]. Both the decrease in protein synthesis and the increase in protein degradation have been shown to be involved in disuse muscle atrophy, and current works have validated elements of both protein synthetic and degradative pathways related to muscle atrophy [21]. Protein turnover vary based on changes in the modes of muscle movement. The changes in physical activity stimulate muscles to adapt, changing fiber size and protein production. The output of these adaptive responses regulates the balance between synthesis and degradation of proteins. When protein degradation exceeds synthesis, atrophy is induced. Therefore, we focused on muscle protein loss related to intracellular signalling during muscle atrophy. Several proteolytic systems responsible for muscle wasting involve the ubiquitin-proteasome, the lysosomal, the caspase and the $\mathrm{Ca}^{2+}$-dependent systems [22]. In disuse atrophy, the ubiquitinproteasome system constitutes a primary signalling pathway of the metabolism, stimulating a mechanism for the selective breakdown of targeted proteins [23].

\section{Overview of the ubiquitin-proteasome system}

The ubiquitin-proteasome system is one of the pathways for targeted protein degradation in mammalian cells. It dissolves into a large amount of intracellular proteins during muscle remodelling, and induces intracellular signalling pathways and physiological protein turnover [24]. The system recognizes damaged and/or misfolded proteins and tags the polypeptide ubiquitin to these targeted proteins. Ubiquitin-tagged proteins are consequently dissolved by a multi-catalytic enzyme complex, 26S-proteasome [25]. In brief, protein degradation by the ubiquitin system composes of a two-step reaction: conjugation of several ubiquitins to the targeted protein and breakdown of the targeted protein by the 26S-proteasome [26]. Conjugation of ubiquitins to the targets proceeds through three successive steps. Initially, the ubiquitinactivating enzyme, E1, activates ubiquitins in its C-terminal Gly. Only one E1 protein has been discovered, an abundant 110-kDa protein necessary for survival [25]. Next, ubiquitin-conjugating enzymes, E2s, and ubiquitin ligases, E3s, cooperate to attach activated ubiquitins to the targets via a peptide bond. Scores of E2 proteins have been discovered, indicating diverse functions of each E2s depending on specific types of targeted proteins. Finally, the targeted protein is catabolized by the 26S-proteasome complex. The 26S-proteasome breaks the substrate in small peptides (3-5 amino acid residues) in an ATP-dependent process. What happens next to these peptides that are broken?

\section{The ubiquitin-proteasome system in disuse muscles}

During physical activity, skeletal muscles undergo mechanical stress. Decreases in mechanical stress as a result of muscle disuse can stimulate the ubiquitin-proteasome system activity, altering activity-related signals. Recent studies demonstrate that the ubiquitin-regulated signals are sensitive to muscle use [27]. The same is true for the conditions when muscle contraction is decreased, including denervation [2830] immobilization [31] and gravitational unloading [23,32]. For example, two E3 proteins, atrogin-1/MAFbx and MuRF1, were elevated during physical inactivity, including hind limb immobilization, gravitational unloading and muscle denervation [28], whereas muscle constriction performed immediately after immobilization instigated a decline in MAFbx and MuRF1 [31]. Reaction of the ubiquitin-proteasome system to changes in muscle movements appears to depend on the duration and intensity of the intervention [33-35]. The changes in the reaction are anticipated to irritate both signalling and proteolysis by degradation of targeted proteins [27]. The myogenic transcription factor MyoD is one such molecular player that is regulated by the ubiquitinproteasome system in muscles. The ubiquitin-proteasome system prevents MyoD signalling by degradation of the MyoD protein [36]. Another is regulation of NF- $\mathrm{KB}$ signalling. NF- $\kappa \mathrm{B}$ signalling has been appreciated as a main pro-inflammatory process, regulating the secretion of other pro-inflammatory molecules like chemokines and cytokines. NF- $\mathrm{KB}$ is up-regulated during tissue inflammation, and also interacts with other cytokines. Ubiquitin

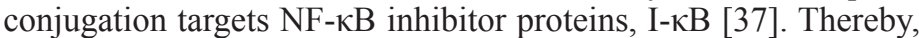

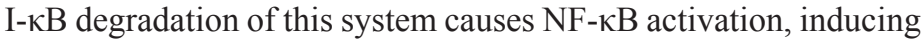
muscle wasting [18].

\section{Inflammation}

\section{Acute inflammation and chronic inflammation}

Inflammation is the physiological response through which the body restores tissue injury and protects itself from stimuli including pathogens and noxious agents. Symptoms of inflammation are redness, swelling, heat and pain. After the initial stimulus, abundant pro-inflammatory cells migrate to the site of inflammation. The event begins with release of chemokines and cytokines from local cells, including macrophages, dendritic cells, vascular endothelial 
cells, and interstitial fibroblasts. Neutrophils are the first proinflammatory cells to arrive at the site, causing secondary damage by releasing proteases and reactive oxygen species (ROS) [38]. Simultaneously, neutrophils promote recruitment and activation of monocytes through the secretion of cytokines and chemokines $[39,40]$. Then, monocytes reached the extravascular tissue, where they transform into macrophages. Activated macrophages (also called M1, below-mentioned) accelerate the mobilization and the activation of pro-inflammatory effector cells, leading to the activation of NF- $\mathrm{kB}$ signalling by interactions with a series of pro-inflammatory cytokines, such as IL- $1 \beta$ and TNF- $\alpha$. Activated macrophages produce such pro-inflammatory cytokines, and play a pivotal role in the onset and progression of inflammation. Activated macrophages are enhancing the ability to phagocytose pathogens, damaged tissues and apoptotic cells, and also produce biologically active molecules that facilitate myoblast (e.g. satellite cells) proliferation. Activated satellite cells begin to proliferate, thereby supplying myonuclei for the formation of new myofibers. Subsequently, anti-inflammatory macrophages (also called M2, below-mentioned) contribute to tissue restoration, during which macrophages secrete IL-10 and transforming growth factor (TGF)- $\beta$ that dampen the initial pro-inflammatory cytokine production. These anti-inflammatory cytokines also support myogenesis and promote wound healing [41]. Such a phenotype shift from pro-inflammatory to anti-inflammatory macrophages are likely induced by engulfment of debris [42]. Prohibition of inflammation through the removal of pro-inflammatory effector cells allows the host to restore tissue damage. The usual outlook of the acute inflammatory pathway is successful resolution and restoration of tissue damage, without sustained inflammation, which can bring about scarring and chronic loss of organ function. Acute inflammation is typically self-limiting, and the tissue is restored to a homeostatic state. Although the accurate mechanisms regulating the shift from pro-inflammatory to anti-inflammatory signalling are not fully identified, the resolution pathway includes apoptosis, anti-inflammatory cytokines, anti-oxidants and protease inhibitors. Notably, macrophages also play a pivotal role in this process. In acute inflammation, if the effectors are eliminated, macrophages eventually return to steady state [43]. Because the resolution process involves dynamic reactions, this process may prolong and perpetuate inflammation. Disruption of mechanisms can cause incomplete recovery and sustained inflammatory conditions. The disruption was brought about by failure to eliminate pathogens, for instance. Insufficient elimination of proinflammatory cells may alter functions of immune cells, affecting resolution-related signalling, and causing chronic inflammation. Chronic inflammation is an extended inflammation, in which tissue damage and recovery coexist, causing to abnormal tissue remodelling and functional disorder. Chronic inflammation begins as a low-grade, pre-manifest response with no symptoms of inflammation (redness, swelling, heat and pain). However, even a low level of inflammation may damage tissue functions. In addition, the sustained progression of tissue damage and recovery promotes abnormal tissue remodelling (e.g. fibrogenesis) that may ultimately cause irreversible functional disorder [44]. A complex interplay between the tissue cells and the various cells in the interstitium, including vascular cells, immune cells and fibroblasts, leads to the process of chronic inflammation under the effects from both the local tissue micro-environment and the rest of the systemic organs. Particular attention is paid to monocyte/macrophage cells, which act as main effector cells in chronic inflammatory pathways [44]. A primary function of macrophages for recovery from inflammation is the clearance of effector cells (especially apoptotic granulocytes [45]) and pathogens. Insufficient clearance of pro-inflammatory molecules by macrophages may also block the resolution, affecting resolution-related signalling and processes. In summary, the diminished macrophage phagocytic ability results in accumulation of damage-associated molecular patterns (DAMPs), eventually resulting in chronic inflammation. More research is needed to clarify how inflammation causes a loss of phagocytic ability of macrophages in future studies.

\section{Cytokines in acute and chronic inflammation}

Inflammation is facilitated by a group of small protein, cytokines. Pro-inflammatory cytokines are classified into two groups: Acute or Chronic Inflammation-related groups [46]. However, some cytokines, such as TNF- $\alpha$, IL-1 and IL-6, contribute to both inflammation pathways. In both acute and chronic inflammation, a variety of cytokines promote expression of cell adhesion molecules and chemoattractant, leading to leukocyte recruitment. Furthermore, cytokines regulate the activation of stromal cells (that is, mast cells, endothelial cells, resident macrophages and fibroblasts) and the induced cells (that is, neutrophils, monocytes, eosinophils and lymphocytes). Some cytokines also mediate the systemic inflammatory response (e.g. fever, leukocytosis and cachexia). This multi-functionality can elicit their effects locally and systemically, orchestrating the inflammatory process.

\section{Cytokines relating to acute inflammation}

Representative cytokines involved in acute inflammation are TNF- $\alpha$, IL-1, IL-6, IL-17 and chemokines (IL-8 and MCP-1) [47]. IL-1 and TNF- $\alpha$ are the primary cytokines in acute inflammation.

\section{IL-1}

IL-1 is mainly secreted by fibroblasts, activated monocytes/ macrophages, keratinocytes, T cells and B cells. IL-1 activates the synthesis of a pyrogenic mediator, prostaglandin $\mathrm{E}_{2}\left(\mathrm{PGE}_{2}\right)$, by hypothalamus [48] and promotes $\mathrm{T}$ cell proliferation. IL-1 also enhances the secretion of histamine from mast cells during inflammation [49]. Histamine leads to vasodilatation and elevation of vascular permeability, which cause redness and swelling [50]. The function of IL-1 is inhibited by the IL-1 receptor antagonist (IL-1ra), which is produced by TNF- $\alpha$ - or GM-CSF-stimulated neutrophils and by IL-4-stimulated macrophages [51].

\section{TNF- $\alpha$}

TNF- $\alpha$ is mainly produced by mast cells, activated monocytes/macrophages, fibroblasts and natural killer (NK) cells [52]. TNF- $\alpha$ can also trigger fever, either directly through promotion of PGE2 synthesis by the hypothalamus, or indirectly 
by stimulating secretion of IL-1 [48]. Both TNF- $\alpha$ and IL-1 can promote the production of PGE2 and collagenase by synovial cells, contributing to joint injury. TNF- $\alpha$ causes further secondary inflammatory effects due to activation of IL-6 synthesis in several cells, namely, the production of acute phase protein by the liver. Like IL- 1 and TNF- $\alpha$, IL- 6 mediates induction of fever and the acute inflammatory signalling, eventually causing the perpetuation of the inflammatory pathway through overlapping functions of cytokines.

\section{Cytokines relating to chronic inflammation}

As the acute inflammation period is prolonged, cytokine interactions lead to monocyte chemotaxis towards the inflammation site, where monocytes differentiate into macrophages. Macrophages are activated by macrophage-activating factors, such as MCP-1 and interferon (IFN) $-\gamma$, and then migration inhibition factors, such as GM-CSF [53] and IFN- $\gamma$, keep them in the inflamed tissue. The cells chronically elevate levels of TNF- $\alpha$ and IL-1, which results in chronic inflammation. The cytokines involved in chronic inflammation are divided into two groups: (a) the humoral immune group (such as IL-3, IL-4, IL-5, IL-6, IL-7, IL-9, IL-10, IL-13, and TGF- $\beta$ ), and (b) the cellular immune group (such as TNF- $\alpha$, IL-1, IL-2, IL-3, IL-4, IL-7, IL-9, IL-10, IL-12, TGF- $\beta$, IFNs and IFN- $\gamma$ inducing factor). Some typical examples are cited as follows.

\section{The humoral immune group}

\section{IL-3}

IL-3 is secreted by T cells. It promotes the differentiation of B cells and eosinophils, while it blocks lymphokine-activated killer cell activity [54].

\section{IL-4}

IL-4 is secreted by CD4+ T cells, basophils and mast cells. CD4+ T cells differentiate intoTh2 cells, not Th1 cells, by IL-4. IL-4 is also a B cell growth factor, operating to switch immunoglobulin class to IgG1 and IgE, by which B cells become to make antibodies $[55,57]$. IL-4 also activates production of collagen $[58,59]$ and IL-6 [60] by fibroblasts, involving in the onset of fibrotic diseases. Meanwhile, IL-4 also exhibits anti-inflammatory properties. It prohibits the secretion of pro-inflammatory cytokines, by synovial membranes of rheumatoid arthritis patients [61].

\section{The cellular immune group}

\section{IL-2}

IL-2 is secreted mainly by Th cells, acting as a growth factor for T cells, B cells and NK cells. As it facilitates the development of lymphokine-activated killer cells [54,62], it regulates both cellular and humoral immune pathways. IL-2 binds to T cells to promote proliferation and production of lymphocytes.

\section{IL-12}

IL-12 is secreted by antigen-presenting cells such as dendritic cells, B cells and macrophages. It is involved in the generation and activation of NK cells, lymphokine-activated killer cells and cytotoxic T cells, IFN- $\gamma$ secretion by $\mathrm{T}$ cells and NK cells, and depression of IgE synthesis [63-65].

\section{Atrophy and inflammation}

The association between disuse muscle atrophy and inflammation remains controversial. Some authors reported that pro-inflammatory cytokines, such as TNF- $\alpha$ [66-69], IFN- $\gamma$ and IL-1 [69] increase ubiquitin-attaching activity in skeletal muscle. In contrast, some authors proposed that the ubiquitin-proteasome system facilitates activation and translocation of NF- $\mathrm{KB}$ into nucleus, as well as a successive reaction that promotes expression of genes for ubiquitin, E2/E3 proteins and proteasome [70-74]. It has also been reported that physical exercise can lead to mitigation of systemic inflammation due to a decrease in pro-inflammatory mediators $[6,47,75]$, and that exercise inhibits infiltration of proinflammatory macrophages and CD8 + T cells [76], suggesting that disuse muscle atrophy and inflammation may interact with each other. A certainty is that disuse muscle atrophy and inflammation exist and are linked intimately in muscle tissues.

\section{The Role of Macrophages in Inflammation}

\section{Origin of macrophages}

Macrophages are generated from three sources. The first is the yolk sac in the embryo, where $\mathrm{F} 4 / 80^{\text {high }}$ macrophage progenitors are yielded. Later, during fetal development, the production of hematopoietic stem cells shifts to the second source, fetal liver. The third source is the bone marrow, which gives rise to monocytes. When incompletely differentiated monocytes reach the extravascular tissue, they transform into monocyte-derived macrophages [77]. Macrophages exist in all organs and connective tissues and are named accordingly for their location, such as microglial cells, osteoclasts, alveolar macrophages and Kupffer cells. In addition to macrophage heterogeneity in different organs and tissues, macrophages can exhibit heterogeneity within a single organ or tissue [78]. Moreover, in the inflammatory condition, after macrophages have differentiated in a microenvironment, whether they are then terminally differentiated, or whether they are functionally flexible and able to adapt their phenotypes depending on changes in their location, have not been elucidated. According to a previous report, most macrophages in the adult tissues were thought to be derived from blood monocytes, which homeostatically replenish tissue-resident macrophage populations [79]. However, studies about the origins of many tissue-resident macrophages have proposed that local proliferation has a way in the regeneration and maintenance of tissue-resident macrophages $[80,81]$. Macrophages were found to invade atrophied myofibers in unloaded soleus muscle [82]. Because macrophages produce multiple biological molecules involved in both pro- and antiinflammation, medical interventions targeting macrophages and macrophage-induced signalling may open new gateways for regulating skeletal muscle atrophy and inflammatory diseases. 


\section{Chemokine family}

The release of MCP-1, a member of chemokine family, is enhanced in damaged skeletal muscle for the recruitment of monocytes/macrophages. Chemokines are typically released by pro-inflammatory cells, and are thought to provide the initiation for the movement of monocytes/macrophages in inflammation, which influences the activation state of immune cells [83]. These factors are classified according to the distribution and the number of cysteine residues near their amino terminals, being named as $\mathrm{C}$, $\mathrm{CC}, \mathrm{CXC}$ or $\mathrm{CX} 3 \mathrm{C}$ chemokines. They show variable specificity and diverse functions. Following muscle injury or disease, chemokines and their receptors are expressed, suggesting that they may be essential in tissue regeneration $[84,85]$. M. Brigitte et al. have reported that the tissue macrophages of skeletal muscle are localized in the epimysium/perimysium and that they release MCP-1 upon muscle injury. Resident macrophages play a key role in the subsequent recruitment of circulating monocytes to the damage cite [86].

\section{Functions of macrophages}

The macrophage is a major cell of the mononuclear phagocyte system that is constructed by cells of bone marrow origin, including circulating monocytes. During inflammation, macrophages exhibit three major functions; (1) antigen presentation, (2) phagocytosis and (3) immunomodulation via secretion of various cytokines and TGFs [87]. Macrophages are crucial for the initiation, persistence and resolution of inflammation due to being controlled their activity in the inflammatory pathway. Activated macrophages are deactivated by anti-inflammatory cytokines (e.g. IL-4, IL-10, IL13 and TGF- $\beta$ ) that are produced by macrophages. Macrophages engage in the auto regulatory loop in the inflammatory pathway [88].

\section{Antigen presentation}

Macrophages act to present antigens for recognition by $\mathrm{T}$ cells and to stimulate the activation of T cells as antigen-presenting cells. The macrophage-cytokine-T cell axis plays a pivotal role in the development of adaptive immunity against specific pathogens.

\section{Phagocytosis}

Macrophages engulf materials to eliminate waste and debris and to kill invading pathogens. Macrophages express receptors, such as mannose receptors, Toll-like receptors (TLRs), seven $\alpha$-helical transmembrane/G protein-coupled receptors and receptors for opsonin. Those receptors exhibit functions by recognizing and binding pathogens, eventually engulfing them [89].

\section{Immunomodulation}

Activated macrophages secrete cytokines, such as TNF- $\alpha$, IL-1，IL-6，IFN- $\alpha / \beta$ ，IL-10，IL-12，IL-18，MCP-1，CX3CL1, urokinase and vascular endothelial growth factor (VEGF). These molecules participate in the control of immune response or inflammatory reaction. For example, IL-12 is a heterodimeric cytokine released primarily by antigen-presenting cells that have important influences in the control of the inflammatory pathway. IL-12 promotes proliferation of T cells and NK cells, stimulates lytic function of activated T cells, and induces IFN- $\gamma$ secretion by T cells and NK cells. IL-12 has a main role in accelerating Th1 immune responses and adaptive immunity [86]. That is, IL-12 acts as a functional bridge between the initial nonspecific innate immunity and the following antigen-specific adaptive immunity [90]. In addition, one of chemokines, MCP-1, stimulates migration of immune cells from the blood to tissues [91].

\section{Classification of macrophage populations: macrophage polarization in tissue repair}

Macrophages are present as functionally different populations at different times during acute inflammation. In general, these populations are assumed to have conflicting functions, being either polarized towards pro-inflammatory or anti-inflammatory activity [92]. Polarized macrophages are presently categorized as either M1 or M2, indicating either classical or alternative activation [93,94]. Despite this dichotomy being, it is important that the M1/M2 dichotomy is not sufficiently established, and that the categorization of macrophages into these two groups is often ambiguous. Pro-inflammatory M1 macrophages emerge from exposure to cytokines, such as IFN- $\gamma$ and TNF- $\alpha$, in addition to bacterial lipopolysaccharide (LPS) or endotoxin $[95,96]$. On the other hand, polarization of M2 macrophages is in complete confusion, including three possible subtypes. However, those exact properties are not elucidated. Alternative M2a macrophages are generally involved in advanced stages of wound healing or regeneration, arising from being challenged by cytokines, such as IL-4 and IL-13. M2b macrophages also exhibit an antiinflammatory function and can secrete large amounts of IL-10. IL-10 is known to give rise to M2c macrophages, which exhibit an anti-inflammatory function. Moreover, M2b also share many functions with tumor-related macrophages [97]. Pro-inflammatory M1 macrophages are found at early stages in a series of muscle restoration after injury or pathogen infection, followed by macrophages having characteristics of the anti-inflammatory M2 phenotype [93]. At an early stage, M1 macrophages phagocytose necrotic cell debris and, in pathogen infection, also accomplish the processing and display of antigens. In addition to releasing large amounts of pro-inflammatory cytokines, M1 macrophages also secrete iNOS, which is needed for killing intracellular pathogens. Alternatively activated M2 macrophages exist in large quantities during the final phase of tissue repair [98], indicating that a variety of M2 macrophage subtypes might act during the muscle restoration process. Despite convincing evidence for the presence of different macrophage populations in muscle restoration, the comprehension of their specific functions is still lacking. Furthermore, the mechanisms in regulating cytokine gene silencing and macrophage deactivation have not been completely explained yet.

\section{Massage}

\section{Massage as an alternative medicine}

Massage is one of the most widespread alternative medicine. 
Recently, there has been an expansion in the use of alternative medicine, and massage is widely appreciated by the general public [99]. Massage may be a safe and beneficial intervention devoid of any major harms or side effects if applied by trained professionals [100]. Massage produces mechanical stress, which is expected to increase muscle extensibility. However, despite its increasing popularity, there remains controversy in the effectiveness of massage as a complementary medicine.

\section{Mechanisms of massage}

Definition of Massage is "a mechanical manipulation of body tissues with rhythmical pressure and stroking for the purpose of promoting health and well-being" [101]. Massage involves several techniques, and their employment depends on the experience of the professional and the intended advantage [102-105]. Massage has long been considered to contribute to wellness via physiological, biomechanical, neurological and psychological mechanisms [105107]. So far, the speculation is that these mechanisms are exerted through mechanostimulation and improve well-being via possible increases in muscle blood flow, as well as possible decreases in neuromuscular excitability. Meanwhile, it has been reported that massage does not alter blood flow for brachial and femoral arteries [108,109], and femoral vein [109]. Inferences on other possible factors are required for further research to understand the mechanisms and benefits of massage. Various physiological factors are affected through massage, with the main factor being mechanical stress. When a mechanical stress is applied to living cells, a complex array of sensors expressing on the surface of the cells is capable of sensing and adapting to the stress. Mechanical stress applied to those sensors activates several kinases such as the mitogen-activated protein kinase (MAPK) and focal adhesion kinase (FAK) family of proteins. These kinase families have further roles in eliciting expression of regulatory factors that modulate the immune cell recruitment, protein synthesis and glucose uptake [110-112]. Therefore, massage applied to body with diverse mechanical stress varies degree of signalling cascade, introducing a positive effect.

\section{The Relationship between Massage and Immune System}

\section{Enhancing immune function by massage}

Some studies have reported that NK cells were increased by the application of massage [113-115]. Breast cancer patients were given massage therapy (45-minute massages, 3 times/ week for 5 weeks) [113]. In the massage therapy group, NK cells were significantly increased. As NK cells are pivotal cytotoxic lymphocytes in the innate immune system, the increase in cell numbers suggests an improved immune function. Diego et al. reported that on HIV patients, NK cells increased following massage intervention [116]. They demonstrate that CD4 cells (cells that are destroyed in HIV) were also increased following massage in the HIV patients. In addition, the patients also reported that they were less depressed by the application of massage. As depression connects immunosuppression in which CD4 number and the CD4/
CD8 ratio were decreased, massage therapy might improve on immune system in the HIV patients [117]. Similar findings were observed for children with asthma [118]. Daily 20-minute massage for asthmatic children by their parents decreased their cortisol level and reduced the occurrence of asthma attack. As cortisol kills NK cells [119], the decrease in cortisol causes the increase in NK cells, and facilitates immune function. In an animal study, following eccentric exercise that caused myofibril damage, rabbits were administered a massage-like stimulation $(0.5 \mathrm{~Hz}, 10 \mathrm{~N}, 15$ minutes $)$ for 4 days [13]. Infiltration of neutrophils and macrophages into the tibialis anterior muscles, decreased and muscle hypofunction was alleviated in the stimulation-administered groups. Furthermore, massage influences the lymphatic system. Proper lymph dynamics are important for an effective immune system and is required to fight infection and in drainage of cell debris, excess interstitial fluid and intestinal toxins from tissues. It is said that the lymphatic system is positively influenced by massage $[115,120,121]$. It was reported that a combination of manual massage and ultrasound application modulated the swelling and fibrosis (12 sessions for 40 minutes each, 3 times/week : ultrasound therapy (Frequency of 3 $\mathrm{MHz}$, continuous mode, intensity of $0.8 \mathrm{~W} / \mathrm{cm}^{2}$, power of $2.8 \mathrm{~W}$ ) followed by the manual lymphatic drainage) [122].

Intensive exercise produces small tears in muscle fibers, leading to inflammation and soreness [123,124]. Crane et al. reported that massage down-regulated the production of NF- $\kappa \mathrm{B}$ and pro-inflammatory cytokines such as TNF- $\alpha$, thereby mitigating dysphoria arising from exercise-induced muscle damage [14]. However, little attention has been paid to the effects of massage on disuse-induced inflammation. Massage may have a connection with the immune system. The improvement of the immune system due to massage will provide the useful therapy toward various diseases. Consequently, although the connection between massage and ubiquitin-proteasome system for promoting disuse muscle atrophy is not still clarified, it is quite likely that abrogation of tissue inflammation due to massage allows inhibition of disuse muscle atrophy.

\section{Mechanical Stress on Skeletal Muscles}

\section{Mechanotransduction}

Skeletal muscles can sense mechanical forces and convert them into physiological signals that regulate protein synthesis. This energy conversion is termed mechanotransduction. To complete this process, the unit that associates extracellular mechanical forces with intracellular biochemical signals is required. The candidates of the units are classified into two groups: the lipid bilayer and extracellular matrix-integrin-cytoskeleton. In this review, we describe the extracellular matrix-integrin-cytoskeleton in the context of immobilization [125,126].

\section{Extracellular matrix-integrin-cytoskeleton}

Recent studies indicate that the cytoskeleton, the focal adhesion (FA) site and dystrophin-glycoprotein complexes are involved in mechanotransduction. The alterations in the structure of (1) FA site and (2) dystrophin-glycoprotein complex of mechanical 


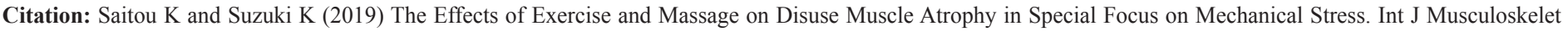
Disord 3: 115. DOI: 10.29011/IJMD-115.1000015

forces enable access to new binding sites, which in turn, activates signalling cascade. The cascade activates MAPKs and PI3K, ultimately leads to regulation of protein synthesis [126].

\section{Focal adhesion site}

FA sites are sites where the extracellular matrix can connect to the intracellular cytoskeleton, and are found at neuromuscular junctions, myotendinous junctions and customers [127]. Proteins at FA sites possess diverse functions. One of the representative proteins is the cell surface receptor, integrin. Integrin is comprised of an extracellular domain, a transmembrane region and a cytoplasmic domain, conjugating the extracellular matrix with cytoskeletal components [128]. The direct connection between the extracellular matrix and cytoskeletal components indicates that integrin could become a mechanosensor that transmits extracellular mechanical forces to the inside of the cells.

\section{Dystrophin-glycoprotein complexes}

The extracellular matrix can also attach to the cytoskeleton by the dystrophin-glycoprotein complexes. In this complex, one of the extracellular matrix proteins, laminin, binds tightly to the transmembranous $\beta$-dystroglycan. $\beta$-Dystroglycan constitutes intracellular connection with dystrophin, and dystrophin establishes a connection with F-actin. As a whole, the coupling between the inside and outside of the cell is accomplished [126].

\section{Muscle deformation}

Muscle contraction and physical load on skeletal muscles bring about muscle deformation [129]. This deformation is a visible change in shape without any change in volume of tissue, in which muscles maintain their volume. Both strains in one direction and compressive loading cause internal stresses in skeletal muscles. The muscles deform due to some force, either internally or externally administered. The most obvious mechanical changes in skeletal muscle are associated with adhesive complexes and cytoskeleton deformation. A cellular deformation induces mechanotransduction in muscle tissue and mechanical stress is transmitted from extracellular matrix to cytoskeleton $[130,131]$.

\section{The relationship of mechanical stress and disuse muscle atrophy}

We conducted a series of experiments using massage-like intervention and showed that massage-like mechanical stimulation (Local cyclical compression: $1 \mathrm{~Hz}, 30$ minutes/day for 7 days) modulated immobilization-induced pro-inflammatory responses of macrophages in situ and alleviated muscle atrophy [132]. When cyclical compression was applied on calves of mice with hindlimb immobilization, the myofibril thickness and contracting forces of calf muscles that are decreased by hindlimb immobilization were partially restored. Notably, cyclical compression tempered the increase in the number of cells expressing pro-inflammatory molecules, TNF- $\alpha$ and MCP-1, including macrophages in situ. Then, by using clodronate liposomes, we induced apoptotic death of phagocytic cells in circulating blood. The reversing effect of cyclic compression of immobilization-induced thinning of myofibers was almost completely nullified in clodronateadministered mice. Furthermore, we validated that cyclical compression induced movement of intramuscular interstitial fluid detected by $\mu \mathrm{CT}$ analysis. Then, we applied pulsatile fluid shear stress on macrophage cells isolated from the abdominal cavity of mice. Pulsatile fluid shear stress reduced the expression of MCP-1 in macrophages in vitro. These results suggested the possible involvement of mechanical stress in disuse muscle atrophy and inflammation, and the critical role of macrophages as a mechanosensor, thereby opening a new path to develop novel therapeutic strategies utilizing mechanical interventions.

\section{Conclusion}

\section{Potential therapeutic role of mechanical stress}

Mechanical stress influences every area of biology, from early developmental process to adult physiology and pathology. In the adult organism, several physiological processes are dependent on mechanical stress sensing, including the senses of hearing and touch. There is also a dark side by pathological forces, such as tumor metastasis and atherosclerosis [133, 134]. Endothelial cells are found at the blood vessel interface and are continually exposed to blood flow (i.e. mechanical stress). Therefore, research on mechanical stress has progressed using endothelial cells as a model system. Endothelial cells possess many mechanosensors on the basal surfaces. These mechanosensors sense blood flow, and convert mechanical tension into biochemical signals [135]. The stress patterns produced by blood flow differ depending on vessel location. These patterns vary from uniform flow to non-uniform perturbed flow. Although endothelial cells sense and differently react to flow patterns specific to their microenvironment, little is known about the basal mechanisms of endothelial mechanosensing. On the other hand, despite exposure to mechanical stress resulting from their shape changes due to muscle contraction, there have been relatively few studies on the underlying mechanisms of skeletal muscle mechanosensing. Much less work has been conducted regarding the biological effects of mechanical stress on the immune system and macrophages. The prevailing studies propose a possibility that monocyte/macrophage-induced mechanic signalling affects tumor development. Mechanosensing is the process, in which various physical stimuli of the extracellular matrix are transduced into biochemical signals to induce cellular actions [136]. Mechanosensing pathways are activated by stimuli to adhesion receptors (e.g. integrin and CD44), leading to changes of downstream signalling and cytoskeletal tension, ultimately regulating many processes for induction of tumor onset and progression [137-139]. However, the role of macrophages has not been made clear. Notably, adhesion receptors on macrophages can also interact with receptors relating to inflammation by sharing similar downstream signalling. Thus, altered extracellular matrix characteristics can modulate immune cell actions indirectly. Very few attempts have been made in clarifying the beneficial 'factors' of physical exercise and massage. In this review, we proposed that the factors were driven from the biological benefits of mechanical stress. These findings clarified the significance of local mechanical stress on cells in situ, which appears to be at 


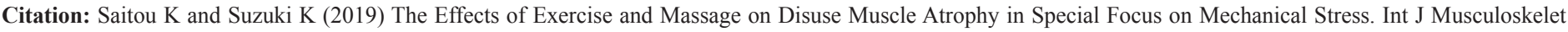
Disord 3: 115. DOI: 10.29011/IJMD-115.1000015

least partly responsible for the positive effects of physical exercise and massage. Understanding the mechanism of mechanical stress provides the scientific evidence for the benefits of moderate exercise and massage and opens a new path to develop a novel therapeutic strategy towards disuse muscle atrophy.

\section{Acknowledgment}

We would like to thank all members of the preventive medicine laboratory. Ms. Ma, Mr. Matsumoto, Ms. Ruhee, Ms. Kim, Mr. Tominaga and Ms. Omae gave us advice. Thanks to their supports, we were able to finish writing this review article. We would also like to thank Dr. Jorming Goh, Ageing Research Institute for Society \& Education, Nanyang Technological University, Singapore for valuable opinions and English editing.

\section{References}

1. Lee IM, Shiroma EJ, Lobelo F, Puska P, Blair SN, et al. (2012) Effect of physical inactivity on major non-communicable diseases worldwide: An analysis of burden of disease and life expectancy. Lancet 380: 219229 .

2. Berg HE, Larsson L, Tesch PA (1997) Lower limb skeletal muscle function after 6 wk of bed rest. J Appl Physiol 82: 182-188.

3. Caron AZ, Drouin G, Desrosiers J, Trensz F, Grenier G (2009) A novel hindlimb immobilization procedure for studying skeletal muscle atrophy and recovery in mouse. J Appl Physiol 106: 2049-2059.

4. Hunter RB, Stevenson E, Koncarevic A, Mitchell-Felton H, Essig DA, et al. (2002) Activation of an alternative NF-KB pathway in skeletal muscle during disuse atrophy. FASEB J 16: 529-538.

5. Winkelman C (2004) Inactivity and inflammation: Selected cytokines as biologic mediators in muscle dysfunction during critical illness. AACN Clin Issues 15: 74-82.

6. Al-Nassan S, Fujita N, Kondo H, Murakami S, Fujino H (2012) Chronic exercise training down-regulates TNF- $\alpha$ and atrogin-1/MAFbx in mouse gastrocnemius muscle atrophy induced by hindlimb unloading. Acta Histochem Cytochem 45: 343-349.

7. Lira FS, Koyama CH, Yamashita AS, Rosa JC, Zanchi NE, et al. (2009) Chronic exercise decreases cytokine production in healthy rat skeletal muscle. Cell Biochem Funct 27: 458-461.

8. Dogra S, Ashe MC, Biddle SJH, Brown WJ, Buman MP, et al. (2017) Sedentary time in older men and women: An international consensus statement and research priorities. Br J Sports Med 51: 1526-1532.

9. Hamilton MT, Healy GN, Dunstan DW, Zderic TW, Owen N (2008) Too little exercise and too much sitting: inactivity physiology and the need for new recommendations on sedentary behavior. Curr Cardiovasc Risk Rep 2: 292-298.

10. Furlan AD, Giraldo M, Baskwill A, Irvin E, Imamura M (2015) Massage for low-back pain. Cochrane Database Syst Rev 9: Cd001929.

11. Robertson A, Watt J, Galloway S (2004) Effects of leg massage on recovery from high intensity cycling exercise. Br J Sports Med 38: 173176.

12. Waters-Banker C, Butterfield TA, Dupont-Versteegden EE (2014) Immunomodulatory effects of massage on nonperturbed skeletal muscle in rats. J Appl Physiol 116: 164-175.
13. Haas C, Butterfield TA, Abshire S, Zhao Y, Zhang X, et al. (2013) Massage timing affects postexercise muscle recovery and inflammation in a rabbit model. Med Sci Sports Exerc 45: 1105-1112.

14. Crane JD, Ogborn DI, Cupido C, Melov S, Hubbard A, et al. (2012) Massage therapy attenuates inflammatory signaling after exerciseinduced muscle damage. Sci Transl Med 4: 119ra13.

15. Ogawa T, Furochi H, Mameoka M, Hirasaka K, Onishi Y, et al. (2006) Ubiquitin ligase gene expression in healthy volunteers with 20 -day bedrest. Muscle Nerve 34: 463-469.

16. Haus JM, Carrithers JA, Carroll CC, Tesch PA, Trappe TA (2007) Contractile and connective tissue protein content of human skeletal muscle: Effects of 35 and 90 days of simulated microgravity and exercise countermeasures. Am J Physiolo-Reg Integ Comp Physiol 293: $1722-1727$.

17. Leblanc A, Rowe R, Schneider V, Evans H, Hedrick T (1995) Regional muscle loss after short duration spaceflight. Aviat Space Environ Med 66: 1151-1154.

18. Hunter RB, Stevenson EJ, Koncarevic A, Mitchell-Felton H, Essig DA, et al. (2002) Activation of an alternative NF-KB pathway in skeletal muscle during disuse atrophy. FASEB J 16: 529-538.

19. Senf SM, Dodd SL, Mcclung JM, Judge AR (2008) Hsp70 overexpression inhibits NF-KB and Foxo3a transcriptional activities and prevents skeletal muscle atrophy. FASEB J 22: 3836-3845.

20. Babij P, Booth FW (1988) Alpha-actin and cytochrome c mRNAs in atrophied adult rat skeletal muscle. Am J Physiol 254: 651-656.

21. Sandri M (2008) Signaling in muscle atrophy and hypertrophy. Physiol (Bethesda) 23: 160-170.

22. Ventadour S, Attaix D (2006) Mechanisms of skeletal muscle atrophy. Curr Opin Rheumatol 18: 631-635.

23. Ikemoto M, Nikawa T, Takeda SI, Watanabe C, Kitano T, et al. (2001) Space shuttle flight (STS-90) enhances degradation of rat myosin heavy chain in association with activation of ubiquitin-proteasome pathway. FASEB J 15: 1279-1281.

24. Mitch WE, Goldberg AL (1996) Mechanisms of muscle wasting. The role of the ubiquitin-proteasome pathway. N Engl J Med 335: 18971905.

25. Lecker SH, Solomon V, Mitch WE, Goldberg AL (1999) Muscle protein breakdown and the critical role of the ubiquitin-proteasome pathway in normal and disease states. J Nutr 129: 227-237.

26. Kandarian SC, Stevenson EJ (2002) Molecular events in skeletal muscle during disuse atrophy. Exerc Sport Sci Rev 30: 111-116.

27. Reid MB (2005) Response of the ubiquitin-proteasome pathway to changes in muscle activity. Am J Physiol Regul Integr Comp Physiol 288: $1423-1431$.

28. Bodine SC, Latres E, Baumhueter S, Lai VK-M, Nunez L, et al. (2001) Identification of ubiquitin ligases required for skeletal muscle atrophy. Science 294: 1704-1708.

29. Medina R, Wing SS, Goldberg AL (1995) Increase in levels of polyubiquitin and proteasome mRNA in skeletal muscle during starvation and denervation atrophy. Biochem J 307: 631-637.

30. Medina R, Wing SS, Haas A, Goldberg AL (1991) Activation of the ubiquitin-ATP-dependent proteolytic system in skeletal muscle during fasting and denervation atrophy. Biomed Biochim Acta 50: 347-356. 


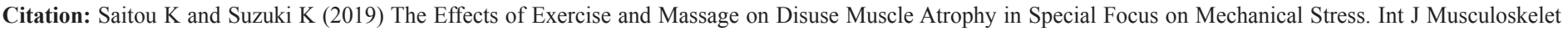
Disord 3: 115. DOI: 10.29011/IJMD-115.1000015

31. Jones SW, Hill RJ, Krasney PA, O'conner B, Peirce N, et al. (2004) Disuse atrophy and exercise rehabilitation in humans profoundly affects the expression of genes associated with the regulation of skeletal muscle mass. FASEB J 18: 1025-1027.

32. Ikemoto M, Nikawa T, Kano M, Hirasaka K, Kitano T, et al. (2002) Cysteine supplementation prevents unweighting-induced ubiquitination in association with redox regulation in rat skeletal muscle. Biol Chem 383: 715-721.

33. Coffey VG, Shield A, Canny BJ, Carey KA, Cameron-Smith D, et al. (2006) Interaction of contractile activity and training history on mRNA abundance in skeletal muscle from trained athletes. Am J Physiol Endocrinol Metab 290: 849-855.

34. Louis E, Raue U, Yang Y, Jemiolo B, Trappe S (2007) Time course of proteolytic, cytokine, and myostatin gene expression after acute exercise in human skeletal muscle. J Appl Physiol 103: 1744-1751.

35. Phillips SM, Tipton KD, Aarsland A, Wolf SE, Wolfe RR (1997) Mixed muscle protein synthesis and breakdown after resistance exercise in humans. Am J Physiol Endocrinol Metab 273: 99-107.

36. Abu Hatoum O, Gross-Mesilaty S, Breitschopf K, Hoffman A, Gonen $\mathrm{H}$, et al. (1998) Degradation of myogenic transcription factor MyoD by the ubiquitin pathway in vivo and in vitro: regulation by specific DNA binding. Mol Cell Biol 18: 5670-5677.

37. Li Y-P, Reid MB (2000) NF-KB mediates the protein loss induced by TNF- $\alpha$ in differentiated skeletal muscle myotubes. Am J Physiol Regul Integr Comp Physiol 279: 1165-1170.

38. Suzuki K (2018) Involvement of neutrophils in exercise-induced muscle damage and its modulation. Gen Int Med Clin Innov 3: 1-8.

39. Lockhart NC, Brooks SV (2008) Neutrophil accumulation following passive stretches contributes to adaptations that reduce contractioninduced skeletal muscle injury in mice. J Appl Physiol 104: 11091115.

40. Pizza FX, Peterson JM, Baas JH, Koh TJ (2005) Neutrophils contribute to muscle injury and impair its resolution after lengthening contractions in mice. J Physiol 562: 899-913.

41. Deng B, Wehling-Henricks M, Villalta SA, Wang Y, Tidball JG (2012) $\mathrm{IL}-10$ triggers changes in macrophage phenotype that promote muscle growth and regeneration. J Immunol 189: 3669-3680.

42. Serhan CN, Savill J (2005) Resolution of inflammation: The beginning programs the end. Nat Immunol 6: 1191-1197.

43. Porcheray F, Viaud S, Rimaniol AC, Leone C, Samah B, et al. (2005) Macrophage activation switching: an asset for the resolution of inflammation. Clin Exp Immunol 142: 481-489.

44. Manabe I (2011) Chronic inflammation links cardiovascular, metabolic and renal diseases. Circ J 75: 2739-2748.

45. Elliott MR, Ravichandran KS (2010) Clearance of apoptotic cells: implications in health and disease. J Cell Biol 189: 1059-1070.

46. Feghali CA, Wright TM (1997) Cytokines in acute and chronic inflammation. Front Biosci 2: 12-26.

47. Suzuki K (2018) Cytokine response to exercise and its modulation. Antioxidants 7: 17-23.

48. Warren JS (1990) Interleukins and tumor necrosis factor in inflamma- tion. Crit Rev Clin Lab Sci 28: 37-59.

49. Conti P, D'Ovidio C, Conti C, Gallenga CE, Lauritano D, et al. (2019) Progression in migraine: Role of mast cells and pro-inflammatory and anti-inflammatory cytokines. Eur J Pharmacol 844: 87-94.

50. Castellani M, Galzio RJ, Felaco P, Tripodi D, Toniato E, et al. (2010) VEGF, substance $P$ and stress, new aspects: a revisited study. J Biol Regul Homeost Agents 24: 229-237.

51. Dinarello CA (1992) Reduction of inflammation by decreasing production of interleukin-1 or by specific receptor antagonism. Int J Tissue React 14: 65-75.

52. Vassalli P (1992) The pathophysiology of tumor necrosis factors. Annu Rev Immunol 10: 411-452.

53. Koike K, Ogawa M, Ihle JN, Miyake T, Shimizu T, et al. (1987) Recombinant murine granulocyte-macrophage (GM) colony-stimulating factor supports formation of GM and multipotential blast cell colonies in culture: comparison with the effects of interleukin-3. J Cell Physiol 131: $458-464$.

54. K Arai, F Lee, A Miyajima, S Miyatake, et al. (1990) Cytokines: coordinators of immune and inflammatory responses. Annu Rev Biochem 59: 783-836.

55. Crosier PS, Clark SC (1992) Basic biology of the hematopoietic growth factors. Semin Oncol 19: 349-361.

56. Patricia BM, Cosman D, Fanslow W, Maliszewski CR, Lyman SD (1992) The interleukin-4 receptor: Structure, function, and signal transduction. Chem Immunol Allergy 51: 107-134.d

57. Yokota T, Arai N, De Vries J, Spits H, Banchereau J, et al. (1988) Molecular biology of interleukin 4 and interleukin 5 genes and biology of their products that stimulate B cells, $T$ cells and hemopoietic cells. Immunol Rev 102: 137-187.

58. Kuhn R, Rajewsky K, Muller W (1991) Generation and analysis of interleukin-4 deficient mice. Science 254: 707-710.

59. Fertin C, Nicolas JF, Gillery P, Kalis B, Banchereau J, et al. (1991) Interleukin-4 stimulates collagen synthesis by normal and scleroderma fibroblasts in dermal equivalents. Cell Mol Biol 37: 823-829.

60. Feghali CA, Bost KL, Boulware DW, Levy LS (1992) Human recombinant interleukin- 4 induces proliferation and interleukin- 6 production by cultured human skin fibroblasts. Clin Immunol Immnopathol 63: 182187.

61. Chomarat P, Vannier E, Dechanet J, Rissoan MC, Banchereau J, et al. (1995) Balance of IL-1 receptor antagonist/IL-1beta in rheumatoid synovium and its regulation by IL-4 and IL-10. J Immunol 154: 14321439.

62. Cohen MC, Cohen S (1996) Cytokine function: A study in biologic diversity. Am J Clin Pathol 105: 589-598.

63. Gately MK, Wolitzky AG, Quinn PM, Chizzonite R (1992) Regulation of human cytolytic lymphocyte responses by interleukin-12. Cell Immunol 143: $127-142$.

64. Kiniwa M, Gately M, Gubler U, Chizzonite R, Fargeas C et al. (1992) Recombinant interleukin-12 suppresses the synthesis of immunoglobulin E by interleukin-4 stimulated human lymphocytes. J Clin Invest 90: $262-266$ 
Citation: Saitou K and Suzuki K (2019) The Effects of Exercise and Massage on Disuse Muscle Atrophy in Special Focus on Mechanical Stress. Int J Musculoskelet Disord 3: 115. DOI: 10.29011/IJMD-115.1000015

65. Scott P (1993) IL-12: Initiation cytokine for cell-mediated immunity. Science 260: 496-497.

66. Li Y-P, Lecker SH, Chen Y, Waddell ID, Goldberg AL et al. (2003) TNF- $\alpha$ increases ubiquitin-conjugating activity in skeletal muscle by up-regulating UbcH2/E220k. FASEB J 17: 1048-1057.

67. Li Y-P, Chen Y, John J, Moylan J, Jin B, et al. (2005) TNF- $\alpha$ acts via p38 MAPK to stimulate expression of the ubiquitin ligase atrogin1/MAFbx in skeletal muscle. FASEB J 19: 362-370.

68. Llovera M, García-MartíNez C, Agell N, López-Soriano FJ, Argilés JM (1997) TNF can directly induce the expression of ubiquitin-dependent proteolytic system in rat soleus muscles. Biochem Biophys Res Commun 230: 238-241.

69. Llovera M, Carbó N, López-Soriano Jn, García-MartíNez C, Busquets $\mathrm{Sl}$, et al. (1998) Different cytokines modulate ubiquitin gene expression in rat skeletal muscle. Cancer Lett 133: 83-87.

70. Cai D, Frantz JD, Tawa NE, Melendez PA, Oh B-C, et al. (2004) Ikk $\beta$ / NF-KB activation causes severe muscle wasting in mice. Cell 119: 285-298.

71. Smith HJ, Wyke SM, Tisdale MJ (2004) Role of protein kinase C and $\mathrm{NF}-\mathrm{KB}$ in proteolysis-inducing factor-induced proteasome expression in C2C12 myotubes. Br J Cancer 90: 1850-1857.

72. Whitehouse AS, Khal J, Tisdale MJ (2003) Induction of protein catabolism in myotubes by 15(S)-hydroxyeicosatetraenoic acid through increased expression of the ubiquitin-proteasome pathway. Br J Cancer 89: $737-475$.

73. Whitehouse AS, Tisdale MJ (2003) Increased expression of the ubiquitin-proteasome pathway in murine myotubes by proteolysis-inducing factor (PIF) is associated with activation of the transcription factor NFKB. Br J Cancer 89: 1116-1122.

74. Wyke SM, Russell ST, Tisdale MJ (2004) Induction of proteasome expression in skeletal muscle is attenuated by inhibitors of NF-KB activation. Br J Cancer 91: 1742-1750.

75. Gleeson M, Bishop NC, Stensel DJ, Lindley MR, Mastana SS et al. (2011) The anti-inflammatory effects of exercise: mechanisms and implications for the prevention and treatment of disease. Nat Rev Immunol 11: 607-615.

76. Kawanishi N, Mizokami T, Yano H, Suzuki K (2013) Exercise attenuates M1 macrophages and CD8+ T cells in the adipose tissue of obese mice. Med Sci Sports Exerc 45: 1684-1693.

77. Sunderkotter C, Nikolic T, Dillon MJ, Van Rooijen N, Stehling M, et al. (2004) Subpopulations of mouse blood monocytes differ in maturation stage and inflammatory response. J Immunol 172: 4410-4417.

78. Gordon S, Plüddemann A, Martinez Estrada F (2014) Macrophage heterogeneity in tissues: phenotypic diversity and functions. Immunol Rev 262: 36-55.

79. Bain CC, Bravo-Blas A, Scott CL, Gomez PE, Geissmann F, et al. (2014) Constant replenishment from circulating monocytes maintains the macrophage pool in the intestine of adult mice. Nat Immunol 15: 929-937.

80. Hashimoto D, Chow A, Noizat C, Teo P, Beasley MB, et al. (2013) Tissue-resident macrophages self-maintain locally throughout adult life with minimal contribution from circulating monocytes. Immunity 38 : 792-804.d
81. Robbins CS, Hilgendorf I, Weber GF, Theurl I, Iwamoto Y, et al. (2013) Local proliferation dominates lesional macrophage accumulation in atherosclerosis. Nat Med 19: 1166-1172.

82. Krippendorf BB, Riley DA (1993) Distinguishing unloading. Versus reloading-induced changes in rat soleus muscle. Muscle Nerve 16: 99-108.

83. Luster AD (1998) Chemokines-chemotactic cytokines that mediate inflammation. N Engl J Med 338: 436-445.

84. Warren GL, O'farrell L, Summan M, Hulderman T, Mishra D, et al. (2004) Role of CC chemokines in skeletal muscle functional restoration after injury. Am J Physiol Cell Physiol 286: C1031-C1036.

85. Warren GL, Hulderman T, Mishra D, Gao X, Millecchia L, et al. (2005) Chemokine receptor CCR2 involvement in skeletal muscle regeneration. FASEB J 19: 413-415.

86. Hokeness KL, Kuziel WA, Biron CA, Salazar-Mather TP (2005) Monocyte chemoattractant protein-1 and CCR2 interactions are required for INF- $\alpha / \beta$-induced inflammatory responses and antiviral defense in liver. $\mathrm{J}$ Immunol 174: 1549-1556.

87. Kasahara T, Matsushima K (2001) Macrophage signaling, apoptosis lectins and leukocyte trafficking. Trends Immunol 22: 593-594.

88. Chatterjee S, Talaat KR, van Seventer EE, Feng CG, Scott AL, et al. (2017) Mycobacteria induce TPL-2 mediated IL-10 in IL-4-generated alternatively activated macrophages. PLoS One 12: e0179701.

89. Takeda K, Kaisho T, Akira S (2003) Toll-like receptors. Annu Rev Immunol 21: 335-376.

90. Kobayashi K, Kaneda K, Kasama T (2001) Immunopathogenesis of delayed-type hypersensitivity. Microsc Res Tech 53: 241-245.

91. Gately MK, Renzetti LM, Magram J, Stern AS, Adorini Le, t al. (1998) The interleukin-12/interleukin-12-receptor system: role in normal and pathologic immune responses. Annu Rev Immunol 16: 495-521.

92. Rot A, Andrian UH (2004) Chemokines in innate and adaptive host defense: basic chemokinese grammar for immune cells. Annu Rev Immunol 22: 891-928.

93. Arnold L, Henry A, Poron F, Baba-Amer Y, Van Rooijen N, et al. (2007) Inflammatory monocytes recruited after skeletal muscle injury switch into antiinflammatory macrophages to support myogenesis. J Exp Med 204: 1057-1069.

94. Wynn TA, Barron L (2010) Macrophages: master regulators of inflammation and fibrosis. Semin Liver Dis 30: 245-257.

95. Mantovani A, Sica A, Sozzani S, Allavena P, Vecchi A, et al. (2004) The chemokine system in diverse forms of macrophage activation and polarization. Trends Immunol 25: 677-686.

96. Wynn TA (2004) Fibrotic disease and the Th1/Th2 paradigm. Nat Rev Immunol 4: 583-594.

97. Biswas SK, Gangi L, Paul S, Schioppa T, Saccani A, et al. (2006) A distinct and unique transcriptional program expressed by tumor-associated macrophages (defective NF-KB and enhanced IRF-3/STAT1 activation). Blood 107: 2112-2122.

98. Wynn TA (2008) Cellular and molecular mechanisms of fibrosis. J Pathol 214: 199-210. 


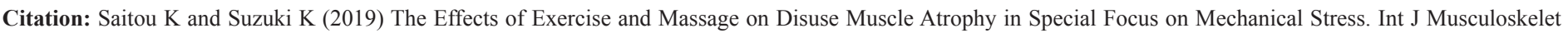
Disord 3: 115. DOI: 10.29011/IJMD-115.1000015

99. Foster DF, Phillips RS, Hamel MB, Eisenberg DM (2000) Alternative medicine use in older Americans. J Am Geriatr Soc 48: 1560-1565.

100. Moraska A (2007) Therapist education impacts the massage effect on postrace muscle recovery. Med Sci Sports Exerc 39: 34-37.

101. Cafarelli E, Flint $F$ (1992) The role of massage in preparation for and recovery from exercise. Sports Med 14: 1-9.

102. Brummitt $J$ (2008) The role of massage in sports performance and rehabilitation: Current evidence and future direction. N Am J Sports Phys Ther 3: 7-21.

103. Netchanok S, Wendy M, Marie C, Siobhan OD (2012) The effectiveness of swedish massage and traditional thai massage in treating chronic low back pain: a review of the literature. Complement Ther Clin Pract 18: 227-234.

104. Perlman Al, Sabina A, Williams A, Njike V, Katz DL (2006) Massage therapy for osteoarthritis of the knee: a randomized controlled trial. Arch Intern Med 166: 2533-2538.

105. Weerapong P, Hume PA, Kolt GS (2005) The mechanisms of massage and effects on performance, muscle recovery and injury prevention. Sports Med 35: 235-256.

106. Braverman DL and Schulman RA (1999) Massage techniques in rehabilitation medicine. Phys Med Rehabil Clin N Am 10: 631-649.

107. Bell AJ (1964) Massage and the physiotherapist. Physiotherapy 50: 406-408.

108. Shoemaker JK, Tiidus PM, Mader R (1997) Failure of manual massage to alter limb blood flow: measures by doppler ultrasound. Med Sci Sports Exerc 29: 610-614.

109. Tiidus PM, Shoemaker JK (1995) Effleurage massage, muscle blood flow and long-term post-exercise strength recovery. Int J Sports Med 16: $478-483$.

110. Cara DC, Kaur J, Forster M, Mccafferty D-M, Kubes P (2001) Role of p38 mitogen-activated protein kinase in chemokine-induced emigration and chemotaxis in vivo. J Immunol 167: 6552-6558.

111. Chambers MA, Moylan JS, Smith JD, Goodyear LJ, Reid MB (2009) Stretch-stimulated glucose uptake in skeletal muscle is mediated by reactive oxygen species and p38 MAP-kinase. J Physiol 587: 33633373.

112. Fan H, Hall P, Santos LL, Gregory JL, Fingerle-Rowson G, et al. (2011) Macrophage migration inhibitory factor and CD74 regulate macrophage chemotactic responses via MAPK and Rho GTPase. J Immunol 186: 4915-4924.

113. Hernandez-Reif M, Field T, Ironson G, Beutler J, Vera Y, et al. (2005) Natural killer cells and lymphocytes increase in women with breast cancer following massage therapy. Int J Neurosci 115: 495-510.

114. Cho KS (1999) The effect of a hand massage program on anxiety and immune function in clients with cataract surgery under local anesthesia. J Korean Acad Nurs 29: 97-106.

115. Ironson G, Field T, Scafidi F, Hashimoto M, Kumar M, et al. (1996) Massage therapy is associated with enhancement of the immune system's cytotoxic capacity. Int J Neurosci 84: 205-217.

116. Diego MA, Field T, Hernandez-Reif M, Shaw K, Friedman L, et al. (2001) HIV adolescents show improved immune function following massage therapy. Int J Neurosci 106: 35-45.
117. Ravindran AV, Griffiths J, Merali Z, Anisman H (1995) Lymphocyte subsets associated with major depression and dysthymia: Modification by antidepressant treatment. Psychosom Med 57: 555-563.

118. Field T, Henteleff T, Hernandez-Reif M, Martinez E, Mavunda K, et al. (1998) Children with asthma have improved pulmonary functions after massage therapy. J Pediatr 132: 854-858.

119. Gupta P, Bigley AB, Markofski M, Laughlin M, LaVoy EC (2018) Autologous serum collected $1 \mathrm{~h}$ post-exercise enhances natural killer cell cytotoxicity. Brain Behav Immun 71: 81-92.

120. Korosec BJ (2004) Manual lymphatic drainage therapy. Home Health Care Management \& Practice 16: 499-511.

121. Chikly BJ (2005) Manual techniques addressing the lymphatic system: origins and development. J Am Osteopath Assoc 105: 457-464.

122. Masson IFB, De Oliveira BDA, Machado AFP, Farcic TS, Júnior IE et al. (2014) Manual lymphatic drainage and therapeutic ultrasound in liposuction and lipoabdominoplasty post-operative period. Indian $\mathrm{J}$ Plast Surg 47: 70-76.

123. Peake J, Nosaka K, Suzuki K (2005) Characterization of inflammatory responses to eccentric exercise in humans. Exerc Immunol Rev 11: 64-85.

124. Tidball JG (2005) Inflammatory processes in muscle injury and repair. Am J Physiol Regul Integr Comp Physiol 288: R345-R353.

125. Plopper GE, Mcnamee HP, Dike LE, Bojanowski K, Ingber DE (1995) Convergence of integrin and growth factor receptor signaling pathways within the focal adhesion complex. Mol Biol Cell 6: 1349-1365.

126. Rando TA (2001) The dystrophin-glycoprotein complex, cellular signaling, and the regulation of cell survival in the muscular dystrophies. Muscle Nerve 24: 1575-1594.

127. Anastasi G, Cutroneo G, Santoro G, Trimarchi F (1998) The non-junctional sarcolemmal cytoskeleton: the costameres. Ital J Anat Embryol 103: 1-11.

128. Schwartz MA, Schaller MD, Ginsberg MH (1995) Integrins: emerging paradigms of signal transduction. Annu Rev Cell Dev Biol 11: 549599.

129. Burkholder TJ (2007) Mechanotransduction in skeletal muscle. Front Biosci 12: 174-191.

130. Pavalko FM, Norvell SM, Burr DB, Turner CH, Duncan RL et al. (2003) A model for mechanotransduction in bone cells: the load-bearing mechanosomes. J Cell Biochem 88: 104-112.

131. Wang N, Butler JP, Ingber DE (1993) Mechanotransduction across the cell surface and through the cytoskeleton. Science 260: 1124-1127.

132. Saitou K, Tokunaga M, Yoshino D, Sakitani N, Maekawa T, et al. (2018) Local cyclical compression modulates macrophage function in situ and alleviates immobilization-induced muscle atrophy. Clin Sci (Lond) 132: 2147-2161.

133. Lucitti JL, Jones EA, Huang C, Chen J, Fraser SE, et al. (2007) Vascular remodeling of the mouse yolk sac requires hemodynamic force. Development 134: 3317-3326.

134. Orr AW, Helmke BP, Blackman BR, Schwartz MA (2006) Mechanisms of mechanotransduction. Dev Cell 10: 11-20. 
Citation: Saitou K and Suzuki K (2019) The Effects of Exercise and Massage on Disuse Muscle Atrophy in Special Focus on Mechanical Stress. Int J Musculoskelet Disord 3: 115. DOI: 10.29011/IJMD-115.1000015

135. Givens C, Tzima E (2016) Endothelial mechanosignaling: does one sensor fit all? Antioxid Redox Signal 25: 373-388.

136. Springer NL, Fischbach C (2016) Biomaterials approaches to modeling macrophage-extracellular matrix interactions in the tumor microenvironment. Curr Opin Biotechnol 40: 16-23.

137. Multhaupt HA, Leitinger B, Gullberg D, Couchman JR (2016) Extracellular matrix component signaling in cancer. Adv Drug Deliv Rev 97: 28-40.
138. Parekh A, Weaver AM (2016) Regulation of invadopodia by mechanical signaling. Exp Cell Res 343: 89-95.

139. Yu FX, Zhao B, Guan KL (2015) Hippo pathway in organ size control, tissue homeostasis, and cancer. Cell 163: 811-828.

140. Suzuki K (2019) Chronic inflammation as an immunological abnormality and effectiveness of exercise. Biomolecules 9(6), 223. 